\title{
Heart failure: A challenging syndrome for health care professionals
}

\author{
Ekaterini Lambrinou ${ }^{1 *}$, Andreas Protopapas ${ }^{1}$ and Fotini Kalogirou ${ }^{2}$ \\ ${ }^{1}$ School of Health Sciences, Cyprus University of Technology, Cyprus \\ ${ }^{2}$ Cambridge University Hospitals, NHS Foundation Trust, England
}

\begin{abstract}
Research and evidence-based practice in heart failure (HF) have well been developed the latest years helping health professionals to cope with multiple care needs of patients with HF. The current review presents an overview of the challenging issues of health professionals who care for patients with HF. The review was based on the relevant databases of PubMed, Cumulative Index to Nursing and Allied Health Literature (CINAHL) and Cochrane Library (reviews and clinical trials). Mortality and impaired quality of life in patients with HF still rises. This is mainly due to the ageing of population and the fact that prevalence of HF is higher in older people. Often HF in order people exists with co-morbidities which make HF diagnosis and management more difficult and complex.
\end{abstract}

\section{Introduction}

Heart failure (HF) is considered as one of the major public health problems worldwide, with a 5-year survival ranging from 50 to $70 \%$, and multiple adverse outcomes; such as hospitalization, death, functional and emotional impairment $[1,2]$. Ageing population, better treatment of myocardial infarction and prolongation of life expectancy of patients with cardiovascular diseases lead to an increasing prevalence of HF, posing a challenge for health care professionals who have to respond to the needs and problems of a population with high prevalence of comorbidities [3-5]. Frequently, non-specific signs and symptoms of HF are covered by those of non-cardiac comorbidities causing diagnostic difficulties, polypharmacy and difficult management of the certain population [3].

There has been an improved survival in patients with HF and reduction in HF mortality due to substantial progress in the management of care of individuals with HF, including pharmacologic therapy, devices and multi-disciplinary approach [6]. Even though, there are existing challenges for health care of patients with HF. First, age-adjusted prevalence rate continues to rise, causing an enormous economic burden to health care systems [1,7-9]. Second, even though the clinical practical guidelines and recommendations promote best clinical practice, surveys have shown variation in adherence to the guidelines and a gap between them and the clinical practice $[10,11]$.

This paper provides an overview of the challenges health professionals may confront when they care HF patients.

\section{Changing demographics and increasing incidence of $\mathrm{HF}$ and co-morbidities}

Advances in cardiology and in medicine in general, have increased life expectancy of individuals with acute and chronic health problems, changing at the same time the demographic and clinical characteristics of patients with HF [3]. Additionally, heart failure risk factors vary substantially among world regions. More detailed regional heart failure epidemiology studies are needed in order to quantify the global burden of heart failure and identify regional prevention and treatment strategies. The increase in HF prevalence is age dependent and the prevalence of $\mathrm{HF}$ is highest in older people. The changing profile of individuals with HF has resulted the fact of multiple comorbid conditions and the need of multiple medications (polypharmacy) along with the challenge of diagnostic difficulty and complex management. HF symptoms are often not typical in older people. Respiratory disorders, depression, obesity and arthritis in older people have common symptoms with those in HF, e.g. dyspnea and fatigue [6]. Other, rarely mentioned concomitant conditions are frailty syndrome (FS), dementia, and orthostatic hypotension $(\mathrm{OH})$ [12], which might adversely affect overall morbidity and mortality. It is not unusual; polypharmacy has drug interactions which may interfere with drug efficacy, and in unpredictable ways. Thus often, early readmissions are not due to cardiac reasons, but due to complications of other diseases or polypharmacy, due to behavioral reasons, such as non-adherence to the therapy and social factors such as social isolation. As it seems, many of those readmissions could be prevented. Age- related physiological changes, functional status, comorbid conditions, patients and health professional's preferences influence the care of older people with heart failure, along with readmission cause [13].

Due to its prevalence among older people, HF might be considered as a geriatric disease as well [6]. Co-morbidities, socio-economic and frailty issues make heart failure a much more complex syndrome than a cardiac pump syndrome. That means that patients receiving solo care

*Correspondence to: Ekaterini Lambrinou, Associate Professor, Department of Nursing, School of Health Sciences, Cyprus University of Technology, 15, Vragadinou str., Limassol 3041, Cyprus, Tel: 00357- 25-002030; Fax: 00357-22103186; E-mail: ekaterini.lambrinou@cut.ac.cy

Key words: heart failure, education, health professionals, cardiologists, nurses, general practitioners, challenges in heart failure, diagnosis of heart failure, treatment of heart failure

Received: June 09, 2018; Accepted: June 20, 2018; Published: June 22, 2018 
from cardiologists, in even specialized heart failure clinics, might not receive appropriate care for other unrelated comorbidities, such as severe arthritis or depression. Depression in older people is common, and the prevalence is higher in HF patients and has been associated with functional decline and increased mortality [14].

Though the high estimations of depression in patients with HF, depression often goes unrecognized and untreated $[15,16]$. The fact that depressive symptoms are often similar to somatic symptoms, e.g. sleep disturbance, fatigue, weak concentration, may partially explain the low diagnose rate of depression in patients with HF [15].

This brings in front the need of the longitudinal care expertise of general practitioners (GPs), the expert knowledge of cardiologists, nurses and all other health professionals involved. The multidisciplinary team must be prepared and well-organized to respond to the multiple needs of older patients with HF, who may enjoy the best possible quality of care and at the same time the most efficient and costeffective one.

\section{Socio-economic challenges}

$\mathrm{HF}$ is an enormous economic burden for health care system and the most common reason for hospitalization of people over 65 years of age $[8,17]$. Unless appropriate preventive strategies and measures are implemented instantly, the prevalence, related complications and total burden of HF and especially in older population, will expand and tax future healthcare systems even more [18]. Hospital services, medications, physician costs, primary healthcare costs and follow-up visits are considered to be the direct costs and lost productivity resulting from morbidity and mortality. Sickness benefit and welfare support are considered to be the indirect cost of healthcare expenditures [19].

Individuals with HF suffer a variety of emotional and physical symptoms that substantially impair their quality of life (QoL), mobility and daily living [20]. The World Health Organization (WHO) defines QoL as "individuals' perceptions of their position in life in the context of the culture and value systems in which they live and in relation to their goals, expectations, standards and concerns" [21]. One of the major challenges for health care professionals in HF management is to maintain and/or improve HF patients' QoL. But the question rising is how often it is evaluated in the clinical practice, even though it is found to be high correlated with the NYHA classification. Additionally, patients with $\mathrm{HF}$ and their families come to difficult dilemmas or face options regarding continuing or not therapeutic interventions, especially when they have to consider about maintaining QoL against life prolongation or survival[22].Unfortunately, during the end of stage time, often patients' preferences are neglected or misperceived; supportive evidence from ESCAPE study has shown that there are patients who prefer to trade almost all survival in order to have better perceived health[23-25]. Therefore, health professionals caring for HF patients and especially those with progressed HF, need an understanding and knowledge of factors that may help them identify patients for whom extension of life is not the priority [26].

Evidence also indicates that HF patients with poor social support have an increased risk for adverse clinical events and are less likely to adhere to treatment, self-care recommendations and maintain their QoL [27-29]. In the general population, positive social support is beneficial in improving coping skills. Gaining sense of control and stability, anxiety and depression, which are two of the most common co-morbidities in HF are eliminated. Therefore, it is an aspect which should not be neglected in the management of the HF [30] and which is also included in the American and European guidelines [2, 31]. Health care professionals need to be familiarized with procedures which facilitate the identification of patients with poor social support in order to be able to adopt practices for lowering their risk of negative events.

\section{Integration of palliative care in clinical practice}

New therapeutic approaches for managing HF have led to a prolonged disability. Meeting the varying needs of patients arising from the vicious cycle of HF intermittent exacerbations, and the anxiety caused by the progressive and fatal course of the syndrome, has shifted the emphasis towards a model of care that integrates palliation. Palliative care is a multidimensional approach and there are certain issues that should be considered when applied. As mentioned in the position statement of ESC for palliative care in HF, beyond symptom assessment there are several psychological, spiritual, social, familyrelated and end-of-life issues that should be addressed [32].

Discussing end-of-life issues is never easy but patient's information needs and preferences should be taken into consideration. New practitioners are not always ideally trained to approach the dying patient; they appear reluctant to discuss end-of-life issues, usually due to low exposure to palliative care during their generic training [33-35]. In the context of holistic care, clinicians should be prepared to initiate open discussions about the end-of-life and should receive proper training that would allow them to confidently interact with the dying patient. Of course, this necessitates the development of advanced communication skills.

Regulating the balance between curative and palliative care is critically important in all chronic illnesses. Achieving a balance in the case of HF becomes more complex and puzzling due to the recurrent serious exacerbations of the syndrome. Decision making could be quite challenging for the health-care professionals especially when it comes to withdrawing assist devices and deactivating implantable defibrillators. Physicians, cardiologists and HF experts should be prepared to face these ethical dilemmas arising mostly at the end stages of HF [36]. Answering the dilemma of withdrawing such treatments does not only concern dying patients, since shocks from implantable devices can cause fear and distress to any patient currying them [37]. Therefore, physicians should act accordingly after weighting the treatment benefits against patient's preferences and risks.

Palliative care in HF is not an approach appointed to a certain profession or health care worker but is a matter that concerns all the members of the multi-disciplinary team, while expanding across all care settings. Comfort relieve from suffering and quality of life maintenance are optimal goals not only for the terminally ill HF patient but for all symptomatic HF patients; thus palliative care should be embodied in several stages of HF when appropriate [32]. For this reason, health care systems need to adapt to the challenge of providing seam-less tailored services by improving linkage and co-ordination among different settings (hospital, home, nursing homes) and professions [38]. All HF patients should have access to palliative care, and clinicians are challenged to respond to multiple and complex patient needs while applying this approach. All the professionals belonging to the HF team should be given opportunities during their training courses to gain in-depth knowledge and expertise in palliative care. This will aid to improve advanced communication and decision-making skills. A more flexible health care system would allow penetration of palliative care to all settings and help health care providers overcome the barriers in providing optimal palliative care. 


\section{Advances in evidence-based practice and research}

Pharmacological therapy for chronic HF includes evidence-based drugs which are ACE-inhibitors, b-blockers, angiotensin receptor blockers and mineralocorticoid receptor antagonists, whereas for the treatment of acute HF (AHF) diuretics, vasodilators and positive inotropic agents are used $[2,39]$. AHF is a major manifestation of HF decompensation and a reason for increased cost of care. However, there is a lack of evidence-based guidelines to support health professionals during the acute phase $[40,41]$. The development of evidence based and comprehensive approach to guide patient's care how and when to use available treatment for AHF remains an urgent unmet need. A comprehensive strategy involving available drugs, devices, ultrafiltration, biomarkers, objective and valid tools, such as VAS for quantification of dyspnea and of course a multi-disciplinary approach to cope with the urgent and at the same time very complex event [41, 42]. Latest ESC and AHA guidelines include suggestions on when to use devices, but health professionals meet the challenge of best timing for each patient, the management of such procedure, including the management of possible complications $[2,31]$. It is questionable how well prepared are health professionals across settings and countries to deal this challenge and the education needs raises again. Additionally, more improved surgery strategies for more minimally invasive approach of device transplantation, devices that are easy to use and also, are cost-effective is an important management issue that also can be put under the umbrella of future research needed.

As referred above, the prevalence of $\mathrm{HF}$ is associated with ageing and older people with HF have much more higher mortality than younger people with HF [43]. The management of older people with HF is often received from primary health settings and is challenging due to co-morbidities and physical changes of ageing. Despite epidemiological facts and challenges of older population with $\mathrm{HF}$, certain population is under-represented to clinical trials [44].

Stem cell and gene therapy are promising for the near future, but research is yet incomplete. Innovative strategies need basic scientists and clinicians to be in close collaboration and combine their experience and expertise for the benefit of HF patients [45-47].

\section{Evidence based practice: how is it translated into clinical practice?}

There is a rich body of evidence regarding the pharmacological and device-based efficacy translated into guidelines and recommendations [2]. Electronic health records, cohort and multi-center studies showed that adherence to guidelines and quality of care provided varies between the physicians, hospitals and countries, even though this would might not be expected taking into consideration the plethora of publications, guidelines and position statements available [11,48-51]. Many clinical trials include pre-randomization and often exclude patients with major comorbidities, documented contra-indications, poor compliance, and prior drug intolerance; nevertheless, the certain target group represents a population often met in clinical practice. So, even though there is an attempt to apply the evidence to all patients, it is unlikely to explain in detail the wide variation in care in both within and between different countries [44]. That also concerns drugs which found to be effective for HF [52]. Most studies have shown that drugs were prescribed at low doses and those high-risk populations, such as older patients and patients with renal failure, were under-treated or prescribed at low dosages. Few although, recent studies have shown that prescription rates of b-blockers, ACE inhibitors and spironolactone have increased, but still do not meet the suggested doses, especially concerning older people and those with renal failure $[11,52,53]$. Older people are at higher risk of side effects of b-blockers, e.g. hypotension, bradycardia and pulmonary events. At the same time, HF in older people often co-exists with co-morbidities which are contraindications for the use of b-blockers, e.g. chronic obstructive pulmonary disease, peripheral artery disease and the risk of postural hypotension and associated neurologic disorders. Nevertheless, if doses are not reached as those in clinical trials the drugs may not be as effective as expected. This should be taken into consideration during titration, and of course in a careful way and under close monitoring. So, how a health professional can be sure? Continued education and multi-education of cardiologists, general practitioners and nurses is required in order to improve the therapeutic management of chronic HF patients, with particular emphasis on the effective doses of drugs required.

Echocardiography varies among settings, despite the guidelines recommendation, even though is considered the reference standard for the diagnosis of heart failure. Early identification and accurate diagnosis gives the chance for an early and effective treatment. This explains the fact that echo is found to be a key predictor of evidence- based therapy $[2,48,53]$. An important percentage (10-25\%) submitted to hospital with primary diagnosis of HF have no assessment documentations of $\mathrm{LV}$ function $[48,51,53]$. That is maybe one of the reasons that HF is underdiagnosed, especially among older people to which symptoms of co-morbidities may cover or mimic HF symptoms. Furthermore, the difficulty of distinguishing HF with preserved ejection fraction from other entities remains a challenge for the clinician [54]. Several skills and in-depth knowledge are needed for the acquisition of competence in performing echocardiography in $\mathrm{HF}$

\section{Multi-disciplinary and non-pharmacologic management}

Recent studies included multi-disciplinary HF clinics, multidisciplinary follow-up, telephone contact, primary care follow-up, and enhanced patient self-care. Most have used specialist personnel with cardiologists and HF specialist nurses within the multi-disciplinary team. The improvement shown in recent studies is maybe due to better knowledge of international guidelines and the results of large therapeutic trials $[11,53]$. Needs are not the same among health professionals. A young person with $\mathrm{HF}$ with left ventricular dysfunction and no co-morbidities has different needs from an older person with $\mathrm{HF}$ and co-morbidities who also needs care from a geriatrician and a general physician. A systematic review of which the trials included multi-professional care with health care specialists in HF showed reduced mortality by $25 \%$, HF hospitalizations by $26 \%$ and all-cause hospitalizations by $19 \%$ [55]. Also, multi-disciplinary programs which are led by nurses are found to be beneficial in terms readmissions [56]. Nurses who use holistic approach care are likely to identify patient's individual needs and are able to coordinate care among all health professionals in the best possible way. Latest guidelines on HF include suggestion for adopting multi-disciplinary approach in HF management [2]. The progressive syndrome of HF makes insufficient to facilitate a holistic approach in the management of heart failure, despite the progress in the therapeutic approaches. Heart failure is a chronic disease and patients are suggested to take an active role in their care and thus become experts of their condition. They are expected to adopt self-management practices that concern adherence to the treatment plan, monitoring symptoms and evaluating the effectiveness of their actions, such as daily weighting, compliance with diet, sodium and fluid intake recommendations. Unfortunately, findings from studies documented knowledge deficits about HF self-management [57] . Nurses who have a better understanding of HF self-management 
may provide a more effective education for the patient. Therefore, strategies to improve nurses' knowledge on HF self-management are needed. Health care professionals and community health programs need to cooperate in order to help the patient gain self-management skills. The milestone of this procedure is continuity and integration of care. All health professionals involved in the management programme have the opportunity to promote self-care management. Nurses who are involved in all stages of care have the opportunity to detect possible obstacles and promote self-management before patient's discharge from the hospital and make sure that the patient participates to a HF management programme [56]. Nurses who have a better understanding It is important for all health professionals in the HF team to learn how to work together, since they have parallel aims of care. In order to achieve productive co-operation health professionals, need to be adaptable, flexible, collaborative team workers with highly developed interpersonal skills which provide motivation and justification for the introduction of more shared learning opportunities [58].

Numerous studies have proved the importance of a multidisciplinary approach which is also recommended in the guidelines [1, 2]. The management though between the settings and countries seems to vary and often patients are under-treated or late diagnosed. Between countries and settings, clinical practice is constrained by variable awareness of the evidence and guidelines, several external obstacles and clinical interest. On the other hand, in clinical trials, researchers are familiar with the evidence and protocols and patient care is supported by research clinicians, physicians and nurses, who assist in follow-up clinical assessment, regularly document pharmacotherapy and possible titration, monitor compliance to the therapy [59]. Multi-disciplinary management approach that is close to the models of care provided in the clinical trials is met differently between countries and centres as well. What may remain common between the settings and countries are the patients with HF. The care is also differentiated according the culture, socio-economic status, educational background and patients and caregivers' wishes [60]. A patient- centred care is the key of creating a partnership between the patient and the health professional and at the same time involving all possible sources and cultural differences. The educational goals all health professionals are much more in common sharing similar difficulties, worries and educational needs. Continuing education of all health professionals on recommended doses, management of complications, early diagnosis and therapy and follow-up, may be beneficial for the prognosis of HF patients. All health professionals with special interest on the care of HF patients must have a knowledge on all diagnostic and therapeutic approaches available for the early diagnose and treatment of patients with HF. For that reason, several educational programs and courses are developed to support health professionals interested on the care of HF patients [61].

\section{Conclusion}

The increased prevalence of HF the last decades might be the result of the ageing population, increasing incidence of $\mathrm{HF}$ and growing awareness and diagnosis of HF. Rapid advances in the management of HF and the population that concerns, which mostly include older people with co-morbidities, make it difficult for health professionals to catch up with evidence and clinical expertise. The care of a HF patient may become very complex, not only due to the disease progress, but also due to multiple factors that should be taken into consideration including burden of disease and therapy, type of outcome, and patient's preferences. The key of care in all spectrum of disease progress is prevention of all stages; from primary prevention to rehabilitation. Risk stratification and early diagnosis might be the most benefit strategies to detect which patient is at high risk for short- or long- term hospitalization, mortality and would benefit from aggressive therapy or palliative care. Heath professional's awareness and education is the milestones to establish early diagnosis, and best possible prognosis and health-related quality of life of patients with HF.

\section{References}

1. McMurray JJ, Adamopoulos S, Anker SD, Auricchio A, Böhm M, et al. (2012) ESC Guidelines for the diagnosis and treatment of acute and chronic heart failure 2012: The Task Force for the Diagnosis and Treatment of Acute and Chronic Heart Failure 2012 of the European Society of Cardiology. Developed in collaboration with t. Eur Heart J 33:1787-1847. [Crossref]

2. Ponikowski P, Voors AA, Anker SD, Bueno H, Cleland JGF, et al. (2016) 2016 ESC Guidelines for the diagnosis and treatment of acute and chronic heart failure: The Task Force for the diagnosis and treatment of acute and chronic heart failure of the European Society of Cardiology (ESC). Developed with the special contribution. Eur Heart $J$ 1-85. [Crossref]

3. Dahlström U (2005) Frequent non-cardiac comorbidities in patients with chronic heart failure. Eur J Heart Fail 7: 309-316. [Crossref]

4. Lambrinou E, Sourtzi P, Kalokerinou A, Lemonidou C (2009) Attitudes and knowledge of the Greek nursing students towards older people. Nurse Educ Today 29: 617-622. [Crossref]

5. Dickson VV, Buck H, Riegel B (2013) Multiple comorbid conditions challenge heart failure self-care by decreasing self-efficacy. Nurs Res 62: 2-9. [Crossref]

6. Mosterd A, Hoes AW (2007) Clinical epidemiology of heart failure. Heart 93: 1137 1146. [Crossref]

7. McMurray JJ, Petrie MC, Murdoch DR, Davie AP (1998) Clinical epidemiology of hear failure: public and private health burden. Eur Heart J 19 Suppl P: P9-16. [Crossref]

8. Stewart S, Jenkins A, Buchan S, McGuire A, Capewell S, et al. (2002) The current cost of heart failure to the National Health Service in the UK. Eur J Heart Fail 4: 361-371. [Crossref]

9. Liao L, Allen LA, Whellan DJ (2008) Economic burden of heart failure in the elderly Pharmacoeconomics 26: 447-462. [Crossref]

10. Remme WJ (2007) Filling the gap between guidelines and clinical practice in heart failure treatment: still a far cry from reality. Eur J Heart Fail 9: 1143-1145. [Crossref]

11. Swennen MHJ, Rutten FH, Kalkman CJ, Yolanda van der Graaf, Alfred P E Sachs, et al. (2013) Do general practitioners follow treatment recommendations from guidelines in their decisions on heart failure management? A cross-sectional study. BMJ Open 3.

12. Huijts M, van Oostenbrugge RJ, Duits A, Burkard T, Muzzarelli S, et al. (2013) Cognitive impairment in heart failure: results from the Trial of Intensified versus standard Medical therapy in Elderly patients with Congestive Heart Failure (TIMECHF) randomized trial. Eur J Heart Fail 15: 699-707. [Crossref]

13. Fried TR, O'Leary JR (2008) Using the experiences of bereaved caregivers to inform patient- and caregiver-centered advance care planning. J Gen Intern Med 23: 16021607. [Crossref]

14. Rustad JK, Stern TA, Hebert KA, Musselman DL (2013) Diagnosis and treatment of depression in patients with congestive heart failure: A review of the literature. Prim Care Companion CNS Disord 15:1-26. [Crossref]

15. Holzapfel N1, Müller-Tasch T, Wild B, Jünger J, Zugck C, et al. (2008) Depression profile in patients with and without chronic heart failure. J Affect Disord 105: 53-62. [Crossref]

16. Watson K, Summers KM (2009) Depression in patients with heart failure: clinical implications and management. Pharmacotherapy 29:49-63. [Crossref]

17. Dunlay SM, Shah ND, Shi Q, Morlan B, VanHouten H, et al. (2011) Lifetime costs of medical care after heart failure diagnosis. Circ Cardiovasc Qual Outcomes 4: 68-75. [Crossref]

18. Berry C, Murdoch DR, McMurray JJ (2001) Economics of chronic heart failure. Eur J Heart Fail 3:283-291. [Crossref]

19. Cook C, Cole G, Asaria P, Jabbour R, Francis DP (2014) The annual global economic burden of heart failure. Int J Cardiol 171: 368-376. [Crossref]

20. Lambrinou E, Kalogirou F, Lamnisos D, Middleton N, Sourtzi P, et al. (2013) Evaluation of the psychometric properties of the Greek version of the Minnesota Living With Heart Failure questionnaire. J Cardiopulm Rehabil Prev 33: 229-233. [Crossref] 
21. Alison Harper (1996) Introduction, administration,scoring and generic version of the Assessment. WHOQOL-BREF.

22. Fried TR, Bradley EH, Towle VR, Allore H (2002) Understanding the treatment preferences of seriously ill patients. N Engl J Med 346: 1061-1066. [Crossref]

23. Phillips RS, Wenger NS, Teno J, Oye RK, Youngner S, et al. (1996) Choices of seriously ill patients about cardiopulmonary resuscitation: correlates and outcomes. SUPPORT Investigators. Study to Understand Prognoses and Preferences for Outcomes and Risks of Treatments. Am J Med 100:128-137. [Crossref]

24. Sulmasy DP, Terry PB, Weisman CS, Miller DJ, Stallings RY, et al. (1998) The accuracy of substituted judgments in patients with terminal diagnoses. Ann Intern Med 128: 621-629. [Crossref]

25. Stevenson LW, Hellkamp AS, Leier CV, Sopko G, Koelling T, et al. (2008) Changing Preferences for Survival After Hospitalization With Advanced Heart Failure. J Am Coll Cardiol 52:1702-1708. [Crossref]

26. Dev S, Clare RM, Felker GM, Fiuzat M, Warner Stevenson L, et al. (2012) Link between decisions regarding resuscitation and preferences for quality over length of life with heart failure. Eur J Heart Fail 14: 45-53. [Crossref]

27. Bennett SJ, Perkins SM, Lane KA, Deer M, Brater DC, et al. (2001) Social support and health-related quality of life in chronic heart failure patients. Qual Life Res 10: 671-682. [Crossref]

28. Luttik ML, Jaarsma T, Moser D, Sanderman R, van Veldhuisen DJ (2005) The importance and impact of social support on outcomes in patients with heart failure: an overview of the literature. $J$ Cardiovasc Nurs 20: 162-169. [Crossref]

29. Sayers SL, Riegel B, Pawlowski S, Coyne JC, Samaha FF (2008) Social support and self-care of patients with heart failure. Ann Behav Med 35: 70-79. [Crossref]

30. Langford CP, Bowsher J, Maloney JP, Lillis PP (1997) Social support: a conceptual analysis. $J A d v$ Nurs 25: 95-100. [Crossref]

31. Yancy CW, Jessup M, Bozkurt B1, Butler J, Casey DE Jr, et al. (2013) 2013 ACCF/ AHA Guideline for the Management of Heart Failure. Circulation 128: e240-e327.

32. Jaarsma T, Beattie JM, Ryder M, Rutten FH, McDonagh T, et al. (2009) Palliative care in heart failure: a position statement from the palliative care workshop of the Heart Failure Association of the European Society of Cardiology. Eur J Heart Fail 11: 433443. [Crossref]

33. Gibbins J, McCoubrie R, Forbes K (2011) Why are newly qualified doctors unprepared to care for patients at the end of life? Med Educ 45: 389-399. [Crossref]

34. Imes CC, Dougherty CM, Pyper G, Sullivan MD (2011) Descriptive study of partners' experiences of living with severe heart failure. Heart Lung 40: 208-216. [Crossref]

35. Barclay S, Momen N, Case-Upton S, Kuhn I, Smith E (2011) End-of-life care conversations with heart failure patients: a systematic literature review and narrative synthesis. Br J Gen Pract 61:e49-62. [Crossref]

36. Kramer DB, Mitchell SL, Brock DW (2012) Deactivation of pacemakers and implantable cardioverter-defibrillators. Prog Cardiovasc Dis 55: 290-299. [Crossref]

37. Friedmann E, Thomas SA, Liu F, Morton PG, Chapa D, et al (2006) Relationship of depression, anxiety, and social isolation to chronic heart failure outpatient mortality. Am Heart J 152:940 e1-8. [Crossref]

38. Lynn J, Adamson DMM (2003) Living well at the end of life. Adapting health care to serious chronic illness in old age. Rand Heal 1-22.

39. Braunwald E (2013) Heart failure. JACC Heart Fail 1: 1-20. [Crossref]

40. Gheorghiade M, Follath F, Ponikowski P, et al. (2010) Assessing and grading congestion in acute heart failure: A scientific statement from the acute heart failure committee of the heart failure association of the European society of cardiology and endorsed by the European society of intensive care medicine. Eur J Heart Fail 12: 423-433. [Crossref]

41. Riley J (2013) Acute decompensated heart failure: diagnosis and management. $\mathrm{Br} \mathrm{J}$ Nurs 22: 1290-1295. [Crossref]

42. Kwong JSW, Yu C-M (2014) Ultrafiltration for acute decompensated heart failure: a systematic review and meta-analysis of randomized controlled trials. Int J Cardiol 172: 395-402. [Crossref]

43. Cleland JG, McDonagh T, Rigby AS, Yassin A, Whittaker T, et al. (2011) The national heart failure audit for England and Wales 2008-2009. Heart 97: 876-886. [Crossref]

44. Lenzen MJ, Boersma E, Reimer WJ, et al. (2005) Under-utilization of evidence-based drug treatment in patients with heart failure is only partially explained by dissimilarity to patients enrolled in landmark trials: A report from the Euro Heart Survey on Heart Failure. Eur Heart J 26: 2706-2713. [Crossref]
45. Lyon A, Harding S (2007) The potential of cardiac stem cell therapy for heart failure. Curr Opin Pharmacol 7: 164-170. [Crossref]

46. Njeim MT, Hajjar RJ (2010) Gene therapy for heart failure. Arch Cardiovasc Dis 103 477-485. [Crossref]

47. Rota M, Leri A, Anversa P (2014) Human heart failure: is cell therapy a valid option? Biochem Pharmacol 88: 129-138. [Crossref]

48. Cleland JG, Cohen-Solal A, Aguilar JC, Dietz R, Eastaugh J, et al. (2002) Management of heart failure in primary care (the IMPROVEMENT of Heart Failure Programme): an international survey. Lancet 360: 1631-1639. [Crossref]

49. Fonarow GC, Yancy CW, Heywood JT; ADHERE Scientific Advisory Committee, Study Group, and Investigators (2005) Adherence to heart failure quality-of-care indicators in US hospitals: analysis of the ADHERE Registry. Arch Intern Med 165: 1469-1477. [Crossref]

50. Komajda M, Lapuerta P, Hermans N, Gonzalez-Juanatey JR, van Veldhuisen DJ, et al (2005) Adherence to guidelines is a predictor of outcome in chronic heart failure: the MAHLER survey. Eur Heart $J$ 26: 1653-1659. [Crossref]

51. Nieminen MS, Brutsaert D, Dickstein K, Drexler H, Follath F, et al. (2006) EuroHeart Failure Survey II (EHFS II): a survey on hospitalized acute heart failure patients: description of population. Eur Heart J 27: 2725-2736. [Crossref]

52. de Groote P, Isnard R, Assyag P, Clerson P, Ducardonnet A, et al. (2007) Is the gap between guidelines and clinical practice in heart failure treatment being filled? Insights from the IMPACT RECO survey. Eur J Heart Fail 9:1205-1211. [Crossref]

53. Teng TH, Hung J, Finn J (2010) The effect of evidence-based medication use on longterm survival in patients hospitalised for heart failure in Western Australia. Med J Aust 192: 306-310. [Crossref]

54. Penicka M, Vanderheyden M, Bartunek J (2014) Diagnosis of heart failure with preserved ejection fraction: role of clinical Doppler echocardiography. Heart 100 68-76. [Crossref]

55. McAlister FA, Stewart S, Ferrua S, McMurray JJJ V (2004) Multidisciplinary strategie for the management of heart failure patients at high risk for admission: A systematic review of randomized trials. J Am Coll Cardiol 44: 810-819. [Crossref]

56. Lambrinou E, Kalogirou F, Lamnisos D, Sourtzi P (2012) Effectiveness of heart failure management programmes with nurse-led discharge planning in reducing re-admissions: A systematic review and meta-analysis. Int J Nurs Stud 49: 610-624. [Crossref]

57. Kalogirou F, Lambrinou E, Middleton N, Sourtzi P (2013) Cypriot nurses' knowledge of heart failure self-management principles. Eur J Cardiovasc Nurs 12: 159-166. [Crossref]

58. Parsell G, Bligh J (1998) Educational principles underpinning successful shared learning. Med Teach 20: 522-529.

59. González-Juanatey JR, Alegría Ezquerra E, Bertoméu Martínez V, Conthe Gutiérrez P, de Santiago Nocito A, et al. (2008) Heart failure in outpatients: comorbidities and management by different specialists. The EPISERVE Study. Rev española Cardiol 61: 611-619. [Crossref]

60. Whitty JA, Stewart S, Carrington MJ, Alicia Calderone,Thomas Marwick, et al. (2013) Patient Preferences and Willingness-To-Pay for a Home or Clinic Based Program of Chronic Heart Failure Management: Findings from the Which? Trial. PLoS One 8. [Crossref]

61. Lopez-Sendon J, Mills P, Weber H, Michels R, Di Mario C, et al. (2007) Recommendations on sub-speciality accreditation in cardiology: The Coordination Task Force on Sub-speciality Accreditation of the European Board for the Speciality of Cardiology. Eur Heart J 28: 2163-2171. [Crossref]

Copyright: (C2018 Lambrinou E. This is an open-access article distributed under the terms of the Creative Commons Attribution License, which permits unrestricted use, distribution, and reproduction in any medium, provided the original author and source are credited. 